\title{
How Much Philosophy in the Philosophy of Science?
}

\author{
Anke Büter • Ramiro Glauer $\cdot$ Holger Lyre
}

Published online: 30 October 2014

(C) Springer Science+Business Media Dordrecht 2014

This supplement serves a double purpose. It presents, on the one hand, a selection of papers devoted to the title question "How much philosophy in the philosophy of science?". On the other hand, it signalizes the newly established cooperation between the German Society for the Philosophy of Science (GWP: Gesellschaft für Wissenschaftsphilosophie) and the Journal for General Philosophy of Science (cf. U. Krohs, H. Pulte and G. Schiemann, Journal for General Philosophy of Science 44:1-2, 2013).

The GWP was founded in Hannover in 2011 and had its inaugural conference in March 2013 [for a report on the "GWP.2013" by H. Lyre see EPSA Newsletter 2 (1) 2013]. The society was launched for several reasons. Albeit the German community of philosophers of science is quite large (roughly, between 40 and 50 full professors of philosophy of science), it is at the same time a rather distributed and dispersed community. This has to do with the university landscape in Germany, which is dispersed rather than being focused on a few main universities and centers. Hence, one idea was to foster the interconnections between the members of the German philosophy of science community on all levels of the academic system. This is particularly important for young researchers like $\mathrm{PhD}$ students and young postdocs. Also, the GWP seeks to maintain fruitful and professional relations to all national and international societies in the field of philosophy of science.

A further motivation for founding the GWP is indicated by our special issue title itself. Over the last decades, philosophy of science has evolved into a number of autonomous subdisciplines, the disciplinary standards of which derive much more from the respective

\footnotetext{
A. Büter $(\bowtie)$

Institut für Philosophie, Universität Hannover, 30167 Hannover, Germany

e-mail: anke.bueter@philos.uni-hannover.de

R. Glauer · H. Lyre

Institut für Philosophie, Universität Magdeburg, 39104 Magdeburg, Germany

e-mail: ramiro.glauer@ovgu.de

H. Lyre

e-mail: lyre@ovgu.de
} 
scientific disciplines on which they focus rather than from any core of common methodological, epistemological or metaphysical principles. As one of the consequences, philosophers of science quite often must make efforts to motivate and even to legitimize their discipline both within their own broader philosophy community and with respect to the various special sciences. In this context, the GWP will help to provide focused institutional support for the academic and scientific interests of philosophers of science.

Finally, of course, the title question is of eminent interest for philosophy of science itself. For many, the development into a number of autonomous philosophy of science subdisciplines seems "to fulfill the dream of philosophy as approaching finally the firm course of science", to quote from the GWP.2013 announcement. "However, the legitimate question arises as to how much philosophy there is in recent philosophy of science. How strongly has philosophy of science moved towards science and, perhaps, away from the philosophical tradition? How is this move to be valued? What are its consequences for the scientific relevance of the work that philosophers of science do? What are its consequences for philosophy of science as a unified and recognizable discipline? And in which direction should philosophy of science move in the near future?"

The following selection of five papers in this special issue addresses these questions from various angles and perspectives. Rather than pursuing a common take on the title question, the papers present a number of exemplary connections between philosophy, philosophy of science, and science that show that the different fields are permeable in many ways and in many directions. For instance, science interacts with ontology (Friebe); methodological considerations of one field can be drawn on for clarifications of another, completely disparate field (Mantzavinos); and particularities of explanations in one discipline can shed light on general philosophical questions (Manafu), as can specific problems of certain research fields (Hillerbrand). Here comes an overview of each contribution.

In "Categoricalism versus Dispositionalism: a Case Study in Metametaphysics", Cord Friebe engages in some meta-metaphysical reflections on the metaphysical status of Humean and Anti-Humean ontologies. He argues that both constitute considerably substantive claims concerning ontology and that neither can be read off contemporary physical theories and thereby fathoms the relation between scientific theory and ontology, the latter being more deeply entrenched in philosophy than the standard Quinean take on Humean categoricalism would have it.

Rafaela Hillerbrand's “Climate Simulations. Uncertain Projections for an Uncertain World" argues that the considerable uncertainties in climate modeling are impossible to quantify, due to the role of tacit knowledge as well as the necessity to draw on many different models in order to generate policy-relevant knowledge. While based on methodological issues of a specific research field, this argument has implications for dealing with uncertainty and complexity in other disciplines, too. Moreover, it demonstrates the relevance of philosophical considerations for policy-making by suggesting a revision of the current IPCC process based on its conclusion.

In "How much Philosophy in the Philosophy of Chemistry", Alexandru Manafu argues that the philosophy of chemistry is replete with philosophical questions. For one, there are questions that come up specifically in the context of chemistry. For another, chemistry provides an ideal case study for questions of reduction and emergence. There are many received procedures for measuring chemical entities and properties and therefore they are better candidates for an investigation of reduction and emergence than are the comparatively less easily investigable entities and properties of, say, psychology.

According to Chrysostomos Mantzavinos' "Text Interpretation as a Scientific Activity", there is a strong parallel between text interpretation and the formation and testing of 
scientific hypotheses. In both cases, hypotheses are formed on the basis of empirical evidence, reasons are given for their support, and they are subsequently tested on the available material. Thus, scientific methods are applied to objects that lie outside the classical domain of philosophy of science which makes them amenable to considerations from philosophy of science. This is an example for the broader philosophical significance of the field.

Last but not least, the position paper of Marie I. Kaiser, Maria Kronfeldner, and Robert Meunier provides an exploration of the general issue of "Interdisciplinarity in Philosophy of Science”. By distinguishing between and reflecting upon different forms of interdisciplinarity, they generate a foundation for discussions of the status of the discipline-for example regarding questions of the methodological unity of philosophy of science or its possible connections to the sciences.

The selection of these papers gives but a small sample of the diverse interrelations between philosophy, philosophy of science, and science and a likewise small sample of the perspectives that can be taken on these interactions. It is a starting point for a continued investigation of philosophy of science and its place among academic fields.

The special issue is completed by a sixth paper that presents a survey-based overview and quantitative analysis of German philosophy of science for the period from 1992 to 2012. Paper and survey have been provided by the group of Gerhard Schurz and his coworkers Matthias Unterhuber and Alexander Gebharter from the Düsseldorf Center of Logic and Philosophy of Science (DCLPS). 